plier in conjunction with a tuned a.c. ampolifier seems to give more accurate results than photographic photometry. The excitation functions of $\mathrm{N}_{2}+$ have broad maxima for the Meinel bands at electron energies of $90 \mathrm{eV}$. and for the first negative bands at $95 \mathrm{eV}$.

In a discussion of the relation of nitrogen atoms to active nitrogen, $P$. Gribbon pointed out that uncertainty still exists about many features of the production and persistence of nitrogen atoms in discharge tubes and the upper atmosphere. W. Hayes (Dublin) discussed the interpretation of the high-multiplicity bands of the manganese halides in the near ultra-violet and gave an account of new work on these spectra which has resulted in the discovery of many new band systems.

T. E. NEviN

\section{SCIENTIFIC COUNCIL FOR AFRICA SOUTH OF THE SAHARA}

\section{REPORT FOR THE YEAR 1952-53}

\section{$\mathrm{T}$}

THE second report of the Scientific Council for Africa South of the Sahara, which covers the year July $1952-J u n e ~ 1953^{*}$, refers to the marked tendency for certain major problems to be considered sub-regionally. There are now soil problem committees meeting in three out of four sub-regions, and this pattern is expected to be followed as collaboration in other subjects develops. Although the mode of operation of the Council has become better defined, the establishment of the secretariat was only completed towards the end of 1952 , and in some directions scientific collaboration has made slow progress.

At the third session of the Council during August 11-14, 1952, at Bukavu (Costermansville), Belgian Congo, special attention was paid to maps and survey, geology, meteorology, zoology, fisheries and social studies. A specialist meeting on fauna research was held during October 1952 in Nairobi, and an inter-African conference on fauna and flora, convened at Bukavu for October 1953, was scheduled to review the international convention of 1933 in the light of subsequent experience and to consider whether any modifications in policy concerning wild-life are required. A meeting of specialists in planning social research was held at Makerere College, Uganda, during February-March 1953, which listed a number of joint projects and statements on organizations and institutes engaged in social research in Africa and on work in progress which are being prepared for the participating countries or sub-regions. A symposium on African hydrobiology and inland fisheries was held at Entebbe, Uganda, in October 1952, and a report including summaries of the papers and discussions is appearing as C.S.A. Publication No. 6.

Much effort has been devoted to the preparation of a comprehensive list of maps available for the whole region, and this list, including special subject maps as well as topographical maps, has been issued as C.S.A. Publication No. 4. A meeting to discuss the possibility of greater co-ordination, particularly in special subject maps, was to be convened after the fourth session of the Council in August 1953. Good progress is reported in the co-ordination of geological

* Scientific Council for Africa South of the Sahara. Publication No. 5: Second Report-July 1952 to June 1953. Pp. 46. (Bukivu Congo Belge: Scientific Council for Africa South of the Sahara, 1953.) work in the various sub-regions, and full agreement is anticipated on the appointment of a geological scientific correspondent to maintain touch with and assist the many geological surveys and other organizations for geological investigation in the region. A project has been developed for the preparation of a climatological atlas of Africa, but it is expected that two or three years will be required to collect and analyse all the data available on rainfall, temperature and winds, etc., and prepare the series of maps. The "Flore du Congo Belge" and the "Flora of East Africa" were enlarged during the year by further publications, and information has been collected for a comprehensive list of taxonomists who are engaged on African problems in the many different groups of plants and animals. During the year particulars of two hundred and forty scientific and technical libraries in Africa south of the Sahara were published in C.S.A. Publication No. 3, and particulars are being collected of the holdings of periodical literature in the libraries of the subregions. Publication of a list of these holdings is to be followed ultimately by the preparation of comprehensive catalogues, at least for the major libraries. Steps have also been taken towards the preparation of a directory of scientific institutes and organizations in the region.

\section{CACAO RESEARCH DURING 1952-53}

$\mathrm{T}$ HE report of the West African Cacao Research Institute for $1952-53^{*}$ is brief, giving little more than notes on the many lines of investigation that are being followed. Studies of the swollen shoot virus are, as usual, prominent, and many of them are systematic observations that have been going on for several years. These include the recording of symptoms produced in young seedlings by new virus strains (whieh are still being found) and crossprotection tests with the view of classification. The search for new alternative hosts goes on, and it is hoped that eventually all species related to Theobroma cacao occurring in the Gold Coast will be tested for susceptibility. Transmission trials with possible new vectors are linked up, on the entomological side, with equally systematic examination of mealybugs and their parasites and predators, and with extensive screening of systemic insecticides for control of vectors.

The chemistry section is attempting, by paper chromatography, to discover differences in composition between healthy and diseased tissues, analysing also the secretions of mealybugs that have fed upon healthy and diseased tissues. The botany section has cultured cambial tissues in vitro from healthy and diseased trees, so far without finding any differences in growth pattern or histology. Other diseases and pests of the cacao tree are receiving attention, especially capsids and the black pod disease caused by Phytophthora palmivora Butler. It is noted that dusting against capsids with DDT seems to have no important deleterious effect on pollinating insects. One dusting machine among a number tried merits further attention. Long-term

* West African Cacao Research Institute, Tafo, Gold Coast : Annual Report April 1952 to March 1953. Pp. 39. (Published on behalf of 
breeding and genetical studies are mentioned, among which the results of extensive interspecific crossing in Theobroma will be awaited with particular interest.

A report* from the Imperial College of Tropical Agriculture, Trinidad, supplements that for the seven years 1945-51 which was reviewed in Nature (173, 115 ; 1954). Much of the work recorded is concerned with the nutrition of the cacao tree. One paper continues (from the earlier report) the description of an experiment comparing the reactions of young cacao to different combinations of shade and manurial treatment. Others deal with mineral injections, rapid chemical tissue tests, leaf sampling, the treatmen of iron chlorosis with the iron complex of ethylene diaminetetraacetic acid, and marginal leaf scorch. Biochemical studies are progressing, with particular reference to establishing a technique for the satisfactory fermentation of small samples. A note on the conditions of fermentation will be of special interest to users of raw cacao. The report also includes useful notes on minor insect pests of cacao in Trinidad.

E. E. Chemsman

* Report on Cacao Research 1952. Pp. 71. (Imperial College of Tropical Agriculture, St. Augustine, Trinidad, B.W.I., 1953.) $8 s$.

\section{THE POLECAT IN WALES}

$\mathrm{L}$ IKE that of several other British mammals, the distribution of the polecat has not yet been fully investigated. Being a creature of the night and mainly haunting sparsely inhabited uplands or the wilder parts of the lowlands, it is a difficult and often inaccessible subject for study. There is the further complication that ferrets, which are apparently not descended from the British polecat but from a North African species, have for many centuries been escaping and crossing with wild polecats so that perhaps nowhere in Britain can the polecat be claimed to be a 'pure' species. It is, according to William Condry (Oryx, 2, No. 4; March 1954), only in Wales and the Marches, probably in Devon and Cornwall, and possibly in the Lake District, that polecats can safely be said to be genuinely wild. Mid-Wales is undoubtedly their stronghold. The animal is really common in the counties of Cardigan, Merioneth, west Montgomery, Radnor and Brecon.

A remarkable feature of the polecat is the variety of habitats in which it can flourish. Polecats are found in Wales from the coast right up into the hills, and are as much at home in sand-dunes and sea-cliffs as they are about lowland farms, wild wooded gorges, or the margin of bogs. Rabbit-meat is their staple food ; but some live quite independently of it, for there are polecats but no rabbits in some of the moorland plantations of the Forestry Commission near the head of the Severn. In such places voles are perhaps their commonest prey.

Polecats seem to be most numerous in the rough, semi-upland, marginal farm country of which there is so much in mid-Wales and which is so often overrun with rabbits. For it is in ground honeycombed with warrens that polecats thrive best, where they find plenty of food and endless underground galleries in which to lie up in the daytime and where they can have their litters in comparative safety. Although they are often found very close to farms they very rarely attack poultry, despite the reputation as chicken killers which they have had since medieval times.
The polecat's future is, to a large extent, tied up with that of the rabbit; for although polecats can live independently of rabbits, they thrive best where rabbits are plentiful. At present the polecat is probably still increasing and, where rabbit trapping is on a small scale, even extending its range.

\section{CHEMICAL PRIMARY PROCESSES IN THE ACTION OF IONIZING RADIATIONS ON WATER : EVIDENCE FROM EXPERIMENTS WITH HEAVY WATER}

\section{By PATRICK KELLY, DR. TYSON RIGG and DR. JOSEPH WEISS}

University of Durham (King's College, Newcastle upon Tyne)

$T^{\prime} T$ is well known that the energy loss of fast 1 particles proceeds through processes of ionization and excitation. On this basis, it was suggested ${ }^{x}$ that the most important chemical primary process in the action of the ionizing radiations on water can be represented by the net reaction :

$$
\mathrm{H}_{2} \mathrm{O} \longrightarrow \mathrm{H}+\mathrm{OH},
$$

leading to the formation of $\mathrm{H}$ atoms and $\mathrm{OH}$ radicals. Afterwards, it was pointed out by Allen'2 that there appeared to be an additional relatively small decomposition of the water molecules leading somehow directly to the formation of molecular hydrogen (and of an equimolecular amount of hydrogen peroxide). It was assumed that this also proceeds via the splitting of water molecules, according to equation (1.1), and that formation of this molecular hydrogen was due to preferential recombination of some of the hydrogen atoms in 'hot spots' along the tracks of the ionizing radiations. However, a number of experimental facts were difficult to reconcile with such a mechanism, based as it is on the intermediate formation of hydrogen atoms.

It was therefore proposed more recently ${ }^{3}$ that this 'molecular yield' might be due to the direct interaction of excited water molecules $\left(\mathrm{H}_{2} \mathrm{O}^{*}\right)$, according to :

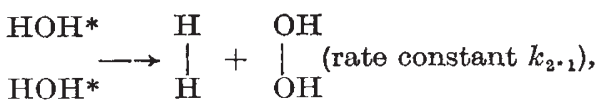

and it was suggested that these processes could take place in the more densely populated clusters along the tracks created by the fast particles, where excited molecules should be formed sufficiently close to each other to enable a bimolecular interaction to occur with some probability ; this would also be consistent with the relatively very low value of the 'molecular' yield.

The problem has been to design an experiment which would allow one to distinguish between : (i) the hydrogen gas formed by the recombination of hydrogen atoms, and (ii) the hydrogen molecules formed directly in a single elementary process.

It has now been found that such information can be derived from a study of the isotopic composition of the hydrogen gas which is given off from water, enriched with heavy hydrogen, under the influence of ionizing radiations. 